\title{
Antigen Mimicry in Autoimmune Disease Sharing of Amino Acid Residues Critical for Pathogenic T Cell Activation
}

\author{
An-Ming Luo, " Kristine M. Garza, " Donald Hunt, ${ }^{*}$ and Kenneth S. K. Tung * \\ Departments of * Pathology and ${ }^{\ddagger}$ Chemistry, University of Virginia, Charlottesville, Virginia 22908
}

\begin{abstract}
A nonamer peptide from murine nicotinic acetylcholine receptor $\delta$ chain (ACR $\delta$ ), which shared four amino acid residues with a nonamer peptide of murine ovarian zona pellucida glycoprotein ZP3, induced murine autoimmune oophoritis and IgG autoantibody to the zona pellucida. Crossreaction between the ACR $\delta$ and ZP3 peptides was established by the response of a ZP3 peptide-specific, oophoritogenic $T$ cell clone to both peptides in association with $I A\left(\alpha^{k} \beta^{b}\right)$. By substituting the ZP3 peptides with a single alanine, four amino acids within the ZP3 peptide were found to be important for ovarian autoimmune disease, autoantibody response, and stimulation of the ZP3-specific $T$ cell clone. Substitution with conservative amino acids of three residues also ablated activity, whereas the fourth, a phenylalanine, was replaceable by tyrosine without loss of activity. Of the four critical amino acids, three were shared between the ZP3 peptide and the ACR $\delta$ peptide. Moreover, polyalanine peptides with the four critical ZP3 amino acids or the four amino acids common to the $Z P 3$ and ACR $\delta$ peptides induced immune response to $\mathrm{ZP3}$ and elicited severe ovarian autoimmune disease. Thus, organ-specific autoimmune disease can occur through immune response against unrelated self (or foreign ) peptides that share with a self-peptide sufficient common amino acid residues critical for activation of pathogenic, autoreactive T cells. (J. Clin. Invest. 1993. 92:2117-2123.) Key words: autoimmune disease $\bullet$ premature ovarian failure $\bullet$ myasthenia gravis • molecular mimicry • peptide vaccines
\end{abstract}

\section{Introduction}

Antigen mimicry has long been proposed as a potential mechanism underlying organ-specific human autoimmune diseases (1). Idiopathic encephalitis, neuritis, and myelitis often occur after viral infection, and autoantibodies have been detected in these patients that react with neural antigens. Investigations in the past have focused on foreign antigenic determinants recognized by autoantibodies (2). Although foreign antigens induced antibody responses that crossreacted with self molecules, autoimmune disease rarely developed in the immunized animals. There are some exceptions. For example, focal encephalomyelitis was induced in rabbits immunized with a peptide from hepatitis B virus; the viral peptide shared common sequence

Address correspondence to Dr. Kenneth S. K. Tung, Department of Pathology, University of Virginia, Box 214, Charlottesville, VA 22908. Received for publication 29 March 1993 and in revised form 15 June 1993.

J. Clin. Invest.

(c) The American Society for Clinical Investigation, Inc. $0021-9738 / 93 / 11 / 2117 / 07 \quad \$ 2.00$

Volume 92, November 1993, 2117-2123 with, and provoked antibody against, the myelin basic protein (3). Another was the induction of myasthenia gravis in rabbits immunized with a chemical analogue of acetylcholine, through induction of antiidiotype antibody that crossreacted with the nicotinic acetylcholine receptor (ACR) $)^{1}(4)$.

Since activation of $\mathrm{T}$ cell response to self-peptides is a pivotal event in the pathogenesis of organ-specific autoimmune diseases, crossreaction between foreign and self-peptides recognized by $T$ cells should, in principle, be more pertinent than autoantibodies in antigen mimicry (5). We have therefore explored this possibility based on a model of murine ovarian autoimmune disease (oophoritis) elicited by a well-characterized ovarian peptide (6).

ZP3 is a glycoprotein in the zona pellucida, its O-linked oligosaccharide being the major sperm receptor in fertilization (7). Within the murine ZP3 sequence (8) is a 13-mer ZP3 peptide (ZP3 330-342) that has two overlapping antigenic domains: ZP3 336-342, a 7-mer linear sequence recognized by ZP3 antibody (9), and ZP3 330-337, the minimal octomer sequence that induces oophoritis, pathology transferrable by pathogenic $\mathrm{CD}^{+} \mathrm{T}$ cells (6). Murine autoimmune oophoritis is a model of human premature ovarian failure in which oophoritis and autoantibodies to ovarian antigens have been documented (10). In addition, premature ovarian failure often coexists with autoimmune adrenalitis, autoimmune thyroiditis, and myasthenia gravis (11). It is currently unclear as to why multiple autoimmune diseases should occur in the same individual. In this paper, we present evidence for antigen mimicry between the murine ZP3 peptide and a peptide from the murine ACR $\delta$ chain (ACR $\delta$ ). Mice immunized with the nonamer ACR $\delta$ peptide developed oophoritis and autoantibodies to the zona pellucida. The evidence for, and the mechanism underlying, the crossreaction between the ZP3 and the ACR $\delta$ peptides will be presented.

\section{Methods}

Induction of murine autoimmune oophoritis. Adult female (C57BL/6 $\times A / J) F_{1}\left(B_{6 A F_{1}}\right)$ mice were purchased from The Jackson Laboratory (Bar Harbor, ME) or the National Cancer Institute (Frederick, MD). Each peptide (at 50- $\mu \mathrm{g}$ dose, dissolved in deionized/distilled water) was emulsified in an equal volume of CFA containing $1 \mathrm{mg} / \mathrm{ml}$ of Mycobacterium tuberculosis (H37Ra; Difco Laboratories, Detroit, MI) or in incomplete Freund's adjuvant (ICFA). Each mouse received $0.1 \mathrm{ml}$ of the peptide and adjuvant emulsion, distributed in the two hind footpads. Histologic evidence of autoimmune oophoritis was determined $14 \mathrm{~d}$ later.

Histology and immunohistochemistry. The ovaries fixed in the Bouin's fixative were embedded in paraffin. Approximately 50 serial step sections per ovary, $5 \mu \mathrm{m}$ thick, were stained with hematoxylin and

1. Abbreviations used in this paper: $\mathrm{ACR}, \mathrm{ACR} \delta$, and $\mathrm{ACR} \gamma$, acetylcholine receptor, $\delta$ and $\gamma$ chains; EAE, experimental autoimmune encephalomyelitis. 
eosin. Histopathology of oophoritis was evaluated as coded specimens, with severity graded from 1 to $4: 1$, focal inflammation in interstitial space; 2 and 3, increasing multifocal inflammatory foci and/or granuloma between and within ovarian follicles; 4 , loss of ovarian follicles and ovarian atrophy (6).

For direct immunofluorescence study, frozen mouse ovaries were embedded in OCT compound, and 5- $\mu$ m-thick sections were cut in a cryostat. After the tissue sections were fixed in $90 \%$ ethanol for $15 \mathrm{~min}$, they were rinsed in PBS and then incubated with fluorescein isothiocyanate-conjugated goat antiserum IgG containing antibody to mouse Igs, IgG heavy chain or IgM heavy chain (Southern Biotechnology, Birmingham, AL) for 30 min. After the sections were rinsed in PBS, a coverslip was applied over glycerol containing 10\% PBS; the images were examined and photographed with a fluorescence microscope (Olympus Corp. of America, New Hyde Park, NY).

Indirect immunoperoxidase technique was used to detect infiltrating $\mathrm{T}$ cells in frozen ovarian sections with the hamster monoclonal anti-mouse CD3 antibody (145-2C11), followed by biotinylated goat antiserum IgG to hamster IgG (Vector Laboratories, Inc., Burlingame, CA). Peroxidase/avidin complex (Vector Laboratories, Inc.) was then applied, and the tissue-bound enzyme was visualized after the tissue section was incubated with 3,3'-diaminobenzidine and fresh $\mathrm{H}_{2} \mathrm{O}_{2}$ (Sigma Chemical Co., St. Louis, MO); the substrate color was intensified by exposure to osmium vapor.

Peptide synthesis, purification, and characterization. Peptides were synthesized by the solid-phase method using the RAMPS system (DuPont Corp., Boston, MA) and purified by high pressure liquid chromatography on a $\mathrm{C} 18$ reverse phase column (Waters Associates, Milford, MA). The purity of all the peptides exceeded $90 \%$. The amino acid sequence was confirmed by mass spectroscopy (12).

Production and proliferation assay of a ZP3 330-342-specific T cell clone. The ZP3 330-342-specific T cell line was produced as described previously (6). Briefly, lymph node cells from $\mathrm{B} \mathrm{AF}_{1}$ mice immunized with $100 \mu \mathrm{g}$ of ZP3 328-342 in CFA were stimulated in vitro with 30 $\mu \mathrm{M}$ of ZP3 $330-342$ in RPMI 1640 supplemented with $1 \%$ sodium pyruvate, $1 \%$ nonessential amino acids, $2 \mathrm{mM}$ glutamine, $100 \mathrm{U}$ penicillin, $100 \mu \mathrm{g} / \mathrm{ml}$ streptomycin, and $5 \times 10^{-5} \mathrm{M}$ 2-mercaptoethanol (Gibco Laboratories, Grand Island, MI), with $10 \%$ heat-inactivated FCS (Sigma Chemical Co.) (complete medium). 4 d later, the lymphocytes were rested in complete medium with $1-2 \%$ of lymphokineenriched supernatant of the cultured EL4 thymoma cell line containing $1.5 \mathrm{U}$ of IL-2 activity. After $10 \mathrm{~d}$, viable lymphocytes were restimulated with $30 \mu \mathrm{M}$ of ZP3 330-342 in complete medium, and rested as above. After four cycles of alternating cell stimulation and rest, a cell line was established that responded specifically to ZP3 330-342. From the T cell line, a ZP3 330-342-specific T cell clone (J3) was obtained by limiting dilution at 0.3 cells per each $200-\mu$ l flat-bottomed well in complete medium containing 1-2\% of EL4 cell culture supernatant. When the $\mathrm{J} 3$ clone reached the growth phase, it was recloned as above at $\mathbf{0 . 3}$ cells per well.

To measure the proliferative response of the $\mathrm{J} 3$ clone, $5 \times 10^{4} \mathrm{~J} 3$ cells were cultured with $5 \times 10^{5}$ antigen-presenting cells and the stimulating peptide at several peptide concentrations in $200 \mu$ l of complete medium. After $4 \mathrm{~d}$ in $37^{\circ} \mathrm{C}$ in $5 \% \mathrm{CO}_{2}$ and air, $0.5 \mu \mathrm{Ci}$ of $\left[{ }^{3} \mathrm{H}\right]-$ thymidine was added; and cell-associated radioactivity was determined in a $\beta$ counter $8 \mathrm{~h}$ later. Data were expressed as delta counts per minute $(\Delta \mathrm{cpm})(\mathrm{cpm}$ in $\mathrm{T}$ cells cultured with antigenic peptide $-\mathrm{cpm}$ in $\mathrm{T}$ cells cultured without antigenic peptide).

The following antigen-presenting cells were used to determine the MHC restriction of the $\mathrm{J} 3$ clone in its response to the ZP3 peptide: irradiated spleen cells from $\mathrm{B}_{\mathrm{AAF}}, \mathrm{A} / \mathrm{J}, \mathrm{C} 57 \mathrm{BL} / 6$, or B10A.5R mice, mitomycin-treated $\mathrm{L}$ cells transfected with murine $\operatorname{IA}\left(\alpha^{\mathrm{k}} \beta^{\mathrm{b}}\right)$ or with murine IA $\left(\alpha^{b} \beta^{k}\right)$ (a generous gift of Dr. Ned Braunstein, Columbia University, New York, NY).

Adoptive transfer of autoimmune oophoritis by the J3 clone. After the ZP3-specific T cell clone ( $\mathrm{J} 3$ ) was stimulated in vitro with $30 \mu \mathrm{M}$ of ZP3 330-342 for $4 \mathrm{~d}$, the viable T cell blasts isolated in a Hypaque-Ficoll gradient were injected intraperitoneally into normal, untreated adult $\mathrm{B} \mathrm{AF}_{1}$ female mice. Ovarian pathology in cell recipients was examined $10 \mathrm{~d}$ after cell transfer.

Cytokine assays. IL-2, IL-4, tumor necrosis factor, and interferon $\gamma$ were quantitated as described elsewhere (13).

Statistical analysis. Significance in disease incidence differences was determined by the chi-square analysis.

\section{Results}

A peptide from murine ACR delta chain elicits murine autoimmune oophoritis. Among truncated ZP3 328-342 peptides, ZP3 330-338 was the shortest oophoritogenic peptide found to stimulate mitogenic response of an oophoritogenic $T$ cell line (6). A search in the protein sequence library revealed two murine ACR peptides that share partial sequence homology with ZP3 330-338: ACR $\delta$ 120-128 and an ACR $\gamma$ peptide, ACR $\gamma$ $117-124$ ( Table I) $(14,15)$. This finding was of potential interest because of the known clinical association between premature ovarian failure and myasthenia gravis.

The peptides ACR $\delta$ 120-128 and ZP3 330-338 share four common amino acid residues. When $\mathrm{B} \mathrm{AF}_{1}$ mice were immunized with ACR $\delta$ 120-128, they developed oophoritis (Table I). In contrast, $\mathrm{B}^{-\mathrm{AF}_{1}}$ mice immunized with $\mathrm{ACR} \gamma$ 117-124, which shared only two common amino acids with ZP3 330338 , did not develop ovarian pathology.

In mice immunized with ACR $\delta$ 120-128, inflammatory infiltrates were noted in ovarian interfollicular spaces and within the Graafian follicles. The infiltrates contained macrophages, multinucleated giant cells, and lymphocytes (Fig. 1 B), of which many were $\mathrm{T}\left(\mathrm{CD}^{+}\right)$cells (Fig. 1 C). The nature and the extent of ovarian histopathology in the ACR $\delta$ 120-128-immunized mice resembled the mild to moderate oophoritis observed in mice immunized with ZP3 330-338 (6). Consistent with oophoritis induced by the ZP3 peptides, mice immunized with ACR $\delta 120-128$ in ICFA also developed ovarian autoimmune disease (6) (Table I).

Although ZP3 330-338 stimulated the ZP3 330-342-specific $T$ cell line to proliferate, $T$ cells from regional lymph nodes of mice immunized with ZP3 330-338 did not proliferate against ZP3 330-338 in vitro (6). We therefore generated an oophoritogenic, ZP3 330-342-specific T cell clone for purpose of exploring $\mathrm{T}$ cell receptor recognition of the ZP3 peptide and the $\mathrm{ACR} \delta$ peptide.

Production and characterization of a murine ZP3 peptidespecific oophoritogenic $T$ cell clone. From an oophoritogenic ZP3-specific T cell line (6), a ZP3 330-342-specific T cell clone ( $\mathrm{J} 3$ ) was obtained by limiting dilution, twice, at 0.3 cells per well. The $\mathrm{J} 3$ clone was $\mathrm{CD}^{+}$; upon activation, it produced IL-2, interferon $\gamma$, and tumor necrosis factor, but not IL-4 (data not shown). As shown in Table II, the J3 clone adoptively transferred oophoritis to untreated $\mathrm{B} \mathrm{AF}_{1}$ adult recipients, but did not transfer orchitis to $\mathrm{B} \mathrm{AF}_{1}$ male recipients. We next determined $\mathrm{MHC}$ restriction of $\mathrm{ZP} 3$ peptide recognition by this clone.

The functional class II MHC molecules expressed on a $\mathrm{B} \mathrm{AF}_{1}$ antigen-presenting cell include $\operatorname{IA}\left(\alpha^{\mathbf{k}} \beta^{\mathbf{k}}\right), \operatorname{IA}\left(\alpha^{\mathbf{b}} \beta^{\mathrm{b}}\right)$, $\operatorname{IA}\left(\alpha^{\mathbf{k}} \beta^{\mathrm{b}}\right), \operatorname{IA}\left(\alpha^{\mathrm{b}} \beta^{\mathrm{k}}\right), \operatorname{IE}\left(\alpha^{\mathrm{k}} \beta^{\mathrm{k}}\right)$, and $\operatorname{IE}\left(\alpha^{\mathbf{k}} \beta^{\mathrm{b}}\right)$. The $\mathrm{J} 3$ clone was found to respond to the ZP3 330-342 only in the presence of irradiated $\mathrm{B} \mathrm{AF} F_{1}$ spleen cells (mean $\Delta \mathrm{cpm}, 138,640$ ) or mitomycin-treated $\mathrm{L}$ cells transfected with $\operatorname{IA}\left(\alpha^{\mathbf{k}} \beta^{\mathbf{b}}\right)$ (mean $\Delta \mathrm{cpm}, 93,692$ ). No response to ZP3 330-342 occurred in the 
Table I. Crossreaction between Murine ZP3 Peptide and Murine Acetylcholine Receptor Delta Chain Peptide for Induction of Autoimmune Oophoritis and Ovary-bound Anti-Zona Pellucida Antibody Response, and for Stimulation of an Oophoritogenic T Cell Clone

\begin{tabular}{|c|c|c|c|c|c|c|}
\hline \multirow[b]{2}{*}{ Adjuvant } & \multirow[b]{2}{*}{ Peptide } & \multirow[b]{2}{*}{ Sequence } & \multicolumn{2}{|c|}{ Oophoritis } & \multirow{2}{*}{$\begin{array}{l}\text { ZP-bound } \\
\text { IgG }\end{array}$} & \multirow{2}{*}{$\begin{array}{l}\text { Proliferative } \\
\text { responses of } \\
\text { the } \mathrm{J} 3 \text { clone }\end{array}$} \\
\hline & & & Incidence (\%) & Severity & & \\
\hline & & & & 1234 & & $\Delta c p m$ \\
\hline CFA & None & & $0 / 5$ & & $0 / 5$ & 302 \\
\hline CFA & ZP3 330-338 & NSSSSQFQI & $5 / 5(100)$ & 0230 & $5 / 5$ & 121,222 \\
\hline CFA & $\operatorname{mACR} \delta 120-128$ & $\underline{\text { NNNDGSFQI }}$ & $3 / 5(60)$ & 1200 & $3 / 5$ & 95,659 \\
\hline CFA & $\mathrm{mACR} \gamma \quad 117-124$ & $\underline{\bar{N} N V D G V \underline{F E V}}$ & $0 / 5$ & & $0 / 5$ & $-2,097$ \\
\hline CFA & None & & $0 / 5$ & & $0 / 5$ & 243 \\
\hline CFA & ZP3 330-338 & NSSSSQFQI & $4 / 5(80)$ & 1120 & $5 / 5$ & 51,364 \\
\hline CFA & mACR $\delta 120-128$ & $\underline{\text { NNNDGSFQI }}$ & $2 / 5(40)$ & 1100 & $3 / 5$ & 15,397 \\
\hline CFA & $\operatorname{mACR} \gamma \quad 117-124$ & $\underline{\text { NNVDGVFEV }}$ & $0 / 5$ & & $0 / 5$ & $-2,734$ \\
\hline ICFA & None & & $0 / 5$ & & $0 / 5$ & 276 \\
\hline ICFA & ZP3 330-338 & NSSSSQFQI & $4 / 4(100)$ & 1120 & $4 / 4$ & 249,314 \\
\hline ICFA & mACR $\delta 120-128$ & NNNDGSFQI & $3 / 4(75)$ & 1110 & $3 / 4$ & 22,021 \\
\hline ICFA & $\operatorname{mACR} \gamma 117-124$ & NNNVDGVFEV & $0 / 5$ & & $0 / 5$ & $-2,683$ \\
\hline
\end{tabular}

In three independent experiments, adult female $\mathrm{B} \mathrm{AF}_{1}$ mice immunized with $50 \mu \mathrm{g}$ of the peptide in adjuvant, or adjuvant alone, were studied 14 $\mathrm{d}$ later. Antibody to zona pellucida is detected by direct immunofluorescence as intense IgG bound to ovarian zona pellucida. The proliferative responses of the ZP3 330-342-specific, oophoritogenic T cell clone, J3, to the peptides $(30 \mu \mathrm{M})$ in presence of mitomycin-treated L cells transfected with $\mathrm{IA}\left(\alpha^{\mathbf{k}} \beta^{\mathrm{b}}\right)$ are expressed as $\Delta \mathrm{cpm}$.

presence of antigen-presenting cells from $\mathrm{A} / \mathrm{J}$ (mean $\Delta \mathrm{cpm}$, 153), C57BL/6 (mean $\Delta \mathrm{cpm}, 94)$, or B10.A(5R) (mean $\Delta \mathrm{cpm}, 93)$ mice, or with $\mathrm{L}$ cells transfected with $\mathrm{IA}\left(\alpha^{\mathrm{b}} \beta^{\mathbf{k}}\right)$ (mean $\Delta \mathrm{cpm},-152$ ). The recognition of the ZP3 330-342 by the $\mathrm{J} 3$ clone was therefore restricted to $\operatorname{IA}\left(\alpha^{\mathbf{k}} \beta^{\mathrm{b}}\right)$. In addition, it was found that 100-fold less ZP3 330-338 was required to stimulate $\mathrm{J} 3$ in the presence of the $\mathrm{L}$ cells transfected with $\mathrm{IA}\left(\alpha^{\mathbf{k}} \beta^{\mathbf{b}}\right)$ than in the presence of $\mathrm{B} \mathrm{AF} \mathrm{F}_{1}$ spleen cells (data not shown). We therefore used the transfected $\mathrm{L}$ cells as antigenpresenting cells in subsequent studies.

Z P3 330-342-specific oophoritogenic $T$ cell clone responds to ACR $120-128$. The oophoritogenic J3 T cell clone proliferated in response to ZP3 330-342 and ACR $\delta$ 120-128, but not to ACR $\gamma$ 117-124 (Table I). Although J3 responded more vigorously against ZP3 330-338 than against ACR $\gamma$ 120-128, the finding establishes crossreaction in $\mathrm{T}$ cell recognition between ZP3 330-338 and ACR $\delta$ 120-128.

Mice immunized with ZP3 330-338 or ACR 120-128 produce autoantibody to the zona pellucida. Antibody to the zona pellucida, of IgG and not IgM class, was detected in ovaries of mice immunized with ACR $\delta 120-128$ or ZP3 330-338, but not in mice immunized with ACR $\gamma$ 117-124 (Table I). The antibody, detectable by direct immunofluorescence, appeared as intense IgG staining in the ovarian zona pellucida (Fig. 1 D)

Because ZP3 330-338 is known to have T cell but not B cell epitope ( $15 \mathrm{a}$ ), induction of antibody to the zona pellucida by ZP3 330-338 or ACR $\delta$ 120-128 was unexpected. Although we will defer a discussion on the basis for the unexpected autoantibody response to the Discussion section, the induction of $\mathrm{T}$ cell-dependent IgG antibody response to zona pellucida by ACR $\delta$ 120-128 provides evidence for the crossreaction between ACR $\delta$ 120-128 and ZP3 330-338 in stimulating helper $T$ cell required for anti-zona pellucida IgG antibody response. Quantitative analysis of the IgG eluted from the ovaries also established that the zona-bound IgG in mice immunized with the ZP3 peptide was highly enriched $(\sim 200-400)$ for antibody to the zona pellucida over serum $\operatorname{IgG}(15 \mathrm{a})$.

Studies of ZP3 330-338 peptides with a single alanine substitution. We next identified the amino acid residues in ZP3 330-338 important for induction of $(a)$ autoimmune oophoritis, $(b)$ anti-zona pellucida antibody, and $(c)$ mitogenic response of the oophoritogenic $\mathrm{T}$ cell clone.

The ZP3 330-338 peptide in which the residue Asn 330, Gln 335 , or Phe 336 was substituted by an alanine did not elicit autoimmune oophoritis (Table III, Study 1). The replacement of $\mathrm{Gln} 337$ by alanine also reduced the oophoritogenic potential of ZP3 330-338 significantly $(P=0.01)$. Mice immunized with these four alanine-substituted ZP3 peptides likewise did not develop antibody to the zona pellucida (Table III). However, when the other amino acid residues of ZP3 330-338 were each substituted by an alanine, the peptides retained their capacity to induce autoimmune oophoritis and zona pellucida antibody ( $P$ values ranged from 0.4 to 0.8 ) (Table III, Study 1).

The proliferative responses of the oophoritogenic $\mathrm{T}$ cell clone to single alanine-substituted ZP3 330-338 were then examined. J3 clone did not respond to ZP3 330-338 with the Phe 336-to-Ala substitution, even at a $100-\mu \mathrm{M}$ peptide concentration. The responses to ZP3 330-338 with alanine substitution at residue Asn 330, Gln 335, or Gln 337 were significantly reduced; the $\mathrm{J} 3$ clone proliferated only at $100-\mu \mathrm{M}$ concentration. In contrast, the responses of the J3 clone to ZP3 330-338 with alanine substitution in position Ser 331 , Ser 332, Ser 333, Ser 334, or Ile 338 were similar to the response to ZP3 330-338 occurring at $1-\mu \mathrm{M}$ peptide concentration (Table III, Study 1). Thus, the four amino acid residues common to ZP3 330-338 and ACR $\delta$ 120-128 included three residues (Asn 330, Phe 336, Gln 337) that were required for activating the oophoritogenic, ZP3 peptide-specific $T$ cell clone.

Studies of ZP3 330-338 substituted with conservative amino acids. We next studied ZP3 330-338 with the following 

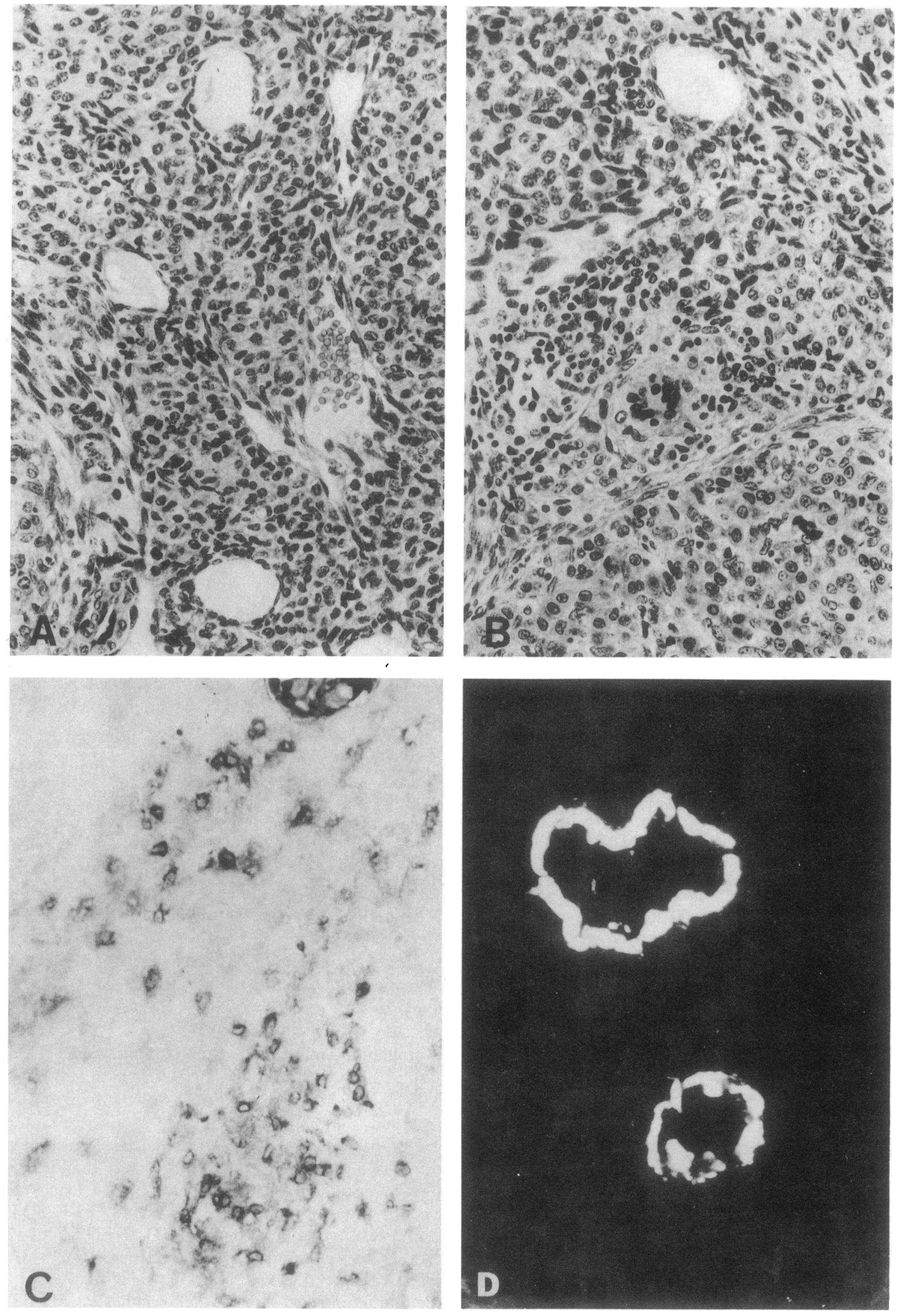

Figure 1. Ovarian immunopathology of a mouse immunized with the murine nicotinic acetylcholine receptor peptide, ACR $\delta 120-128$. Compared with normal mouse ovary $(A)$, which is free of identifiable inflammatory leukocytes, the ovarian interstitial space of a mouse immunized with ACR $\delta$ 120-128 in CFA contains infiltrates of mononuclear inflammatory cells that include a multinucleated giant cell $(B)$. In a mouse immunized with the ACR $\delta$ 120-128 in CFA, $\mathrm{T}\left(\mathrm{CD}^{+}\right)$cells identified by immunoperoxidase are found in the ovarian inflammatory infiltrate $(C)$, and intense staining of mouse IgG (zona pellucida antibody) is detectable by direct immunofluorescence in the ovarian zona pellucida (D) $(A$ and $B, \times 100 ; C$ and $D, \times 400)$. 
Table II. Adoptive Transfer of Autoimmune Oophoritis by the ZP3 330-342 Peptide-specific T Cell Clone to Normal B6AF, Mice

\begin{tabular}{llccc}
\hline & & & \multicolumn{2}{c}{ Pathology incidence } \\
\cline { 5 - 5 } $\begin{array}{l}\text { T cell } \\
\text { clone }\end{array}$ & $\begin{array}{c}\text { Antigen } \\
\text { specificity }\end{array}$ & Cell number & Oophoritis & Orchitis \\
\hline & & $\times 10^{6}$ & & \\
J3 & ZP3 330-342 & $1-20$ & $26 / 29(90 \%)$ & $0 / 10$ \\
D6 & Testis homogenate & 10 & $0 / 6$ & $29 / 38(76 \%)$
\end{tabular}

$\mathrm{J} 3$ clone was obtained from $\mathrm{B}_{6} \mathrm{AF}_{1}$ female mice and $\mathrm{D} 6$ clone from male $\mathrm{B} \mathrm{AF}_{1}$ mice. Generation and characterization of the D6 clone have been described (13). T cell clones were injected intraperitoneally and histopathology of the testis and the ovary was evaluated $10 \mathrm{~d}$ later. Recipients of both clones were free of pathology outside the gonads.

conservative single amino acid substitutions: Asn 330 with Gln, Gln 335 with Asn, Phe 336 with Tyr, Gln 337 with Asn. Peptides with substitution at Asn 330, Gln 335, or Gln 337 did not elicit autoimmune oophoritis or autoantibody to the zona pellucida; and they did not stimulate the J3 clone (Table III, Study 2). In contrast, the peptide with the Phe 336-to-Tyr substitution retained full capacity to induce oophoritis and autoantibody response to zona pellucida, and it stimulated proliferation of the $\mathrm{J} 3$ clone at peptide concentration of $0.1 \mu \mathrm{M}$ (Table III, Study 2).

Study of polyalanine peptides with insertion of selected amino acid residues of ZP3 330-338 and of ACR 120-128. Here, we positively identify the amino acid residues in ZP3 330-338 and ACR $\delta$ 120-128 that are sufficient to elicit au- toimmune oophoritis, anti-zona pellucida antibody response, and stimulation of the oophoritogenic $\mathrm{J} 3$ clone.

We first studied the substituted polyalanine peptide, NAAAAQFQA, which contained the four amino acid residues in ZP3 330-338 shown by the single alanine scan to be important for inducing autoimmune oophoritis. $\mathrm{B} \mathrm{AF}_{1}$ mice immunized with the NAAAAQFQA peptide developed severe oophoritis and autoantibody to zona pellucida (Table III, Study 3 ). We next studied the polyalanine peptide that contained the amino acids common to ZP3 330-338 and ACR $\delta$ 120-128 (NAAAAAFQI). The NAAAAAFQI peptide also induced severe oophoritis and autoantibody response to the zona pellucida, and the ovarian pathology was actually more severe than those observed in mice immunized with ACR $\delta$ 120-128. In parallel, the J3 clone responded vigorously to both NAAAAQFQA and NAAAAAFQI peptides (Table III, Study $3)$. In contrast, the peptide NAAAAAFAA, which contained the two common amino acid residues shared between $\mathrm{ZP3}$ 330-338 and ACR $\gamma$ 117-124, did not induce ovarian disease or autoantibody, nor did not stimulate the J3 clone to proliferate.

\section{Discussion}

This study has demonstrated that a nonamer peptide from mouse ACR $\delta$, which has four amino acid residues in common with a mouse ovarian ZP3 nonamer peptide, is recognized by a pathogenic ZP3 peptide-specific T cell clone, and the recognition was restricted by the same class II MHC molecule. Importantly, $\mathrm{B}_{6 \mathrm{AF}} \mathrm{F}_{1}$ mice actively immunized with the $\mathrm{ACR} \delta$ peptide developed ovarian autoimmune disease. Their ovarian inflammatory infiltrates contained numerous $T$ cells, and they developed autoantibody of the IgG class that bound to the zona

Table III. Mapping the Amino Acid Residues in ZP3 330-338 Important for Induction of Autoimmune Oophoritis and Anti-Zona Pellucida Antibodies, and for Stimulation of an Oophoritogenic T Cell Clone

\begin{tabular}{|c|c|c|c|c|c|c|c|c|}
\hline \multirow[b]{2}{*}{ Study } & \multirow{2}{*}{$\begin{array}{l}\text { Peptide } \\
\text { sequence }\end{array}$} & \multicolumn{2}{|c|}{ Oophoritis } & \multirow{2}{*}{$\begin{array}{c}\text { Zona-bound } \\
\text { IgG }\end{array}$} & \multicolumn{4}{|c|}{ Proliferation of $\mathrm{J} 3$ clone $(\Delta \mathrm{cpm})$} \\
\hline & & Incidence & Severity & & 0.1 & 1 & 10 & 100 \\
\hline & & $\%$ & 1234 & & & & & \\
\hline \multirow[t]{10}{*}{1} & NSSSSQFQI & $9 / 10(90)$ & 1350 & $10 / 10$ & 169 & 12,216 & 32,874 & 249,315 \\
\hline & $\underline{\text { ASSSSQFQI }}$ & $0 / 9(0)$ & 0000 & $0 / 9$ & -185 & 518 & 600 & 46,739 \\
\hline & NASSSSQFQI & $8 / 9(90)$ & 2321 & $6 / 9$ & -56 & 25,924 & 51,738 & 236,450 \\
\hline & NSĀASSQFQI & $10 / 10(100)$ & 2260 & $4 / 5$ & 1,756 & 34,433 & 85,815 & 219,133 \\
\hline & NSSÁSQFQI & $5 / 5(100)$ & 0131 & $5 / 5$ & 835 & 44,120 & 79,919 & 167,197 \\
\hline & NSSSÁQFQI & $6 / 10(60)$ & 2220 & $3 / 5$ & -167 & 1,046 & 34,234 & 141,256 \\
\hline & NSSSSĀFQI & $0 / 9(0)$ & 0000 & $0 / 5$ & -194 & -206 & 637 & 15,810 \\
\hline & NSSSSQAQQI & $0 / 9(0)$ & 0000 & $0 / 9$ & -218 & -225 & 86 & 398 \\
\hline & NSSSSQFËI & $4 / 10(40)$ & 3100 & $2 / 5$ & -211 & -225 & -33 & 7,048 \\
\hline & NSSSSQFQA & $5 / 5(100)$ & 0122 & $4 / 5$ & 36,211 & 37,337 & 211,861 & 241,213 \\
\hline \multirow[t]{4}{*}{2} & QSSSSQFQI & $0 / 5(0)$ & & $0 / 5$ & -163 & 3 & 259 & 997 \\
\hline & NSSSSNFQI & $0 / 5(0)$ & & $0 / 5$ & -3 & 348 & 964 & 2,142 \\
\hline & NSSSSQYQI & $3 / 5(60)$ & 0111 & $4 / 5$ & 6,262 & 28,758 & 197,601 & 310,881 \\
\hline & NSSSSQFNI & $0 / 5(0)$ & & $0 / 5$ & 25 & 1,663 & 1,663 & 3,082 \\
\hline \multirow[t]{3}{*}{3} & NAAAAQFQA & $8 / 10(80)$ & 3320 & $8 / 10$ & 27,284 & 109,783 & 158,031 & 89,808 \\
\hline & NAAAAAFQI & $13 / 15(87)$ & 3730 & $15 / 15$ & 30,769 & 64,960 & 124,713 & 121,605 \\
\hline & NAAAAAFAA & $0 / 10(0)$ & & $0 / 7$ & $-2,615$ & $-2,039$ & 1,295 & 11,456 \\
\hline
\end{tabular}

The results of the in vivo experiments in studies 1 and 3 are pooled from two independent experiments; those of study 2 are from one experiment. The proliferative responses of the $\mathrm{J} 3$ clone to the various peptides are highly reproducible and the result of a representative experiment is shown. 
pellucida in vivo. Of the four amino acids shared by the two unrelated self peptides, three were important for $(a)$ activation of the oophoritogenic T cell clone, $(b)$ induction of autoimmune oophoritis, and $(c)$ development of zona pellucida autoantibodies. To address the evidence for $\mathrm{T}$ cell mimicry directly, we studied a polyalanine peptide with the shared amino acid residues between the ACR $\delta$ and the ZP3 peptides. We then compared this peptide with the polyalanine peptide that contained the four critical amino acid residues of the ZP3 peptide. Both substituted polyalanine peptides were as active as the nonamer ZP3 peptide with respect to oophoritis and autoantibody induction, and in stimulation of the oophoritogenic $\mathrm{T}$ cell clone. It would appear that the sharing of the three critical amino acid residues between the ZP3 and ACR $\delta$ peptides might be the minimal requirement for oophoritis induction. The murine ACR $\gamma$ peptide, which had only two of the critical amino acid residues in common with the ZP3 peptide, did not induce disease or autoimmune responses to ZP3. We conclude that the ACR $\delta$ peptide elicits ovarian autoimmune disease through activation of ZP3 330-338-specific pathogenic T cells, and this occurs when the two unrelated peptides share sufficient critical amino acid residues to stimulate a pathogenic $T$ cell. We should emphasize that pathogenic self-reactive $\mathrm{T}$ cells against ovarian antigen exist in normal mice since mature $\mathrm{CD}^{+}{ }^{+}$thymocytes and $\mathrm{T}$ cells in the peripheral $\mathrm{T}$ cell pool of normal adult female mice, when transferred to athymic recipients, caused autoimmune oophoritis (16).

The induction of antibody response to the zona pellucida by ACR $\delta$ 120-128 was an unexpected but an important observation. We have recently shown that mice immunized with oophoritogenic ZP3 peptides that contained T cell epitope but not $B$ cell epitope can elicit antibody response to antigenic determinants of the $\mathrm{ZP} 3$ protein outside the immunizing peptide ( $15 \mathrm{a}$ ). The study provides evidence that in the presence of endogenous ovarian antigens, activation of ZP3-specific $\mathrm{T}$ cell per se is sufficient to provide the helper $T$ cell signal for an autoantibody response against zona pellucida antigens, including ZP3. First, the truncated ZP3 T cell peptides that lack the region 336-342 were found not to have additional $B$ cell epitopes; indeed, the region 336-342 was the only B cell epitope in ZP3 330-342 recognized in native zona pellucida. Second, antibodies to the zona pellucida were demonstrated both in the serum and ovarian zona pellucida of mice immunized with these truncated ZP3 peptides; and by immunoblot analysis, the serum antibody reacted with ZP3. Third, IgG eluted from the zona pellucida was enriched $200-400$-fold in antibody activity to the zona pellucida over serum IgG, as determined by immunofluorescence and ELISA, but was not enriched for antibody to the 336-342 determinant. Finally, when ovariectomized mice were immunized with the ZP3 T cell peptide, they did not have serum antibody to the zona pellucida, thus the endogenous ovarian zona pellucida is the likely source of antigenic stimulus for the amplified autoantibody response to the zona pellucida.

The finding that ACR $120-128$ also has the capacity to induce autoantibody to the zona pellucida provides strong evidence that the ACR $\delta$ peptide is also recognized by, and can activate, ZP3 peptide-specific helper T cells. Even more important, it demonstrates clearly that mimicry strictly at the level of $T$ cell epitope can lead to immunologic events beyond the induction of $\mathrm{T}$ cell response and autoimmune disease. That is, $\mathrm{T}$ cell epitope mimicry alone can evoke an autoantibody response against the native protein antigen. Therefore, it is quite possible that research that focuses on autoantibodies could minimize or mask the importance of $\mathrm{T}$ cell-mediated immunity in organ-specific, and perhaps systemic, autoimmune disease. On the other hand, the zona pellucida autoantibodies in mice immunized with a T cell peptide of ZP3 preferentially reacted with the native determinants of $\mathrm{ZP} 3$ and were bound to the zona pellucida in vivo; thus they are potentially relevant in autoimmune disease pathogenesis (15a). We have recently uncovered antigen mimicry between ZP3 330-338 and exogenous antigenic peptides (Garza and Tung, preliminary findings). They include (a) a torpedo $\mathrm{ACR} \gamma$ peptide, which shared three of the four critical amino acids with ZP3 330-338 but differs from murine ACR $\gamma$ 117-124 in one of these three amino acid residues, and $(b)$ a viral peptide. Immunization of $\mathrm{B} \mathrm{AF} \mathrm{F}_{1}$ mice with each of these exogenous peptides led to autoimmune oophoritis and autoantibodies to the zona pellucida. Thus, the mechanism of antigen mimicry between ZP3 330-338 and ACR $\delta$ 120-128 does not appear to be an isolated experimental observation.

We have not yet determined whether the critical amino acid residues in the ZP3 330-338 peptide are required for binding to IA $\left(\alpha^{\mathbf{k}} \beta^{\mathbf{b}}\right)$ or as contact sites with the oophoritogenic T cell receptor. In this regard, the finding on the phenylalanine residue in ZP3 336 is of interest. The oophoritogenicity of ZP3 330-338 was lost when Phe 336 was replaced by alanine but not by tyrosine. We have since obtained evidence that the ZP3 peptide retained oophoritogenic activity when Phe 336 was replaced with hydrophobic but not polar amino acid residues (Garza and Tung, preliminary findings). Thus, Phe 336 may be critical by virtue of the chemical property required for interaction with the MHC molecule or the $\mathrm{T}$ cell receptor. The finding of amino acid residues in $\mathrm{T}$ cell epitopes with functions replaceable by some but not other unrelated amino acids is not new (17), and has also been documented in another self peptide of the myelin basic protein (18).

Antigen mimicry has long been proposed as an event that might trigger human organ-specific autoimmune diseases (19). The possibility that autoimmune disease could be induced through antigen mimicry of $\mathrm{T}$ cell epitopes was initially documented in study on a peptide from a Escherichia coli protein. The peptide was found to share sequence homology with the $S$ retinal protein, and rats immunized with the $E$. coli peptide led to autoimmune uveitis and $T$ cell response to the $S$ peptide (20). However, the study neither established $\mathrm{T}$ cell cross-reaction between the peptides nor investigated the mechanism behind the observed phenomenon. Moreover, very large doses of the $E$. coli peptide (400-2,000 $\mu \mathrm{g}$ ) were required to elicit eye pathology. Two recent studies have also explored $\mathrm{T}$ cell epitope mimicry by a novel approach. On the basis of the protocol that recreated the $T$ cell epitopy of a ribonuclease peptide (21), polyalanine peptides were synthesized that contained the critical amino acid residues of the encephalitogenic peptide of the myelin basic protein $(18,22)$. These peptides not only stimulated proliferation of encephalitogenic $T$ cell clone, they induced experimental autoimmune encephalomyelitis (EAE) as well.

The impetus behind our study was initially to elucidate the mechanism for concurrence of autoimmune ovarian disease and myasthenia gravis. Whereas antigen mimicry remains a potential mechanism behind multiple clinical autoimmune diseases, the recently published amino acid sequence of human ZP3 has ruled out direct extrapolation of our experimental findings to the concurrence of the two human diseases (23). 
The murine and human ZP3 330-338 sequences are highly variant, whereas their ACR $\delta$ 120-128 sequences are identical.

This study has important implications for peptide vaccines from foreign proteins that elicit $\mathrm{T}$ cell responses, where, similar to experimental autoimmune disease induction, individuals would be vaccinated with a peptide (24). On the basis of this and other studies $(18,22)$, it is clear that molecular mimicry for autoimmune disease induction requires merely a few randomly positioned amino acid residues $(<50 \%)$ of a self-peptide. Therefore, the potential target self-peptides are not likely detectable by the vaccine peptide probes (antibody or oligonucleotide). Moreover, even if the critical amino acid residues in the vaccine peptide for $T$ cell activation are known, to search for self target peptides with shared amino acid residues is experimentally difficult if not impossible. Finally, powerful adjuvants such as myobacterial components or pertussis toxin are not always required for induction of experimental autoimmune diseases. Although they are obligatory for induction of murine EAE (19) and murine experimental autoimmune orchitis (25), they are not required for murine autoimmune oophoritis (6).

With respect to antigen mimicry in spontaneous autoimmune diseases, it may be argued that immune response to a small peptide does not represent a likely event by which the human disease is triggered. In responses against self proteins that are subjected to tolerance regulation, there is evidence that the pathogenic peptides within a self-protein may be cryptic. Their immunogenicity is manifested only when presented to the host as synthetic peptides and not as the natural sequences of the whole protein $(26,27)$. However, this finding may not apply to responses against $T$ cell epitopes in microbial protein antigens. Spontaneous immune response to microbial agents is complex; and infections, through unknown mechanisms, have been found to terminate an experimentally induced tolerance state (28-30). Microbial superantigens may bypass the tolerance state by coactivating V $\beta$-specific self-reactive T cells (31). Therefore, whether a peptide in a microbe that mimics a self peptide can function as a potent immunogen during an infection remains to be determined experimentally.

\section{Acknowledgments}

We are grateful to Drs. Ya-Huan Lou and Terecita Yule for their valuable assistance in the study, and to Dr. Richard Hodes for helpful contribution in experimental design. We thank Fairley McElveen and Janet Gorman for expert technical assistance and Sharon Burr for preparation of the manuscript.

The study was supported by National Institutes of Health grant HD-29099, Contraceptive Research and Development Program grant CSA-090-071, and U.S. Agency for International Development. AnMing Luo was supported by a fellowship from the World Health Organization. Kristine M. Garza is supported under a National Science Foundation Graduate Research Fellowship. The peptide used for generation of $\mathrm{T}$ cell clone was synthesized at the Salk Institute (under Contract N01-HD-0-2906 with NIH) and made available by the Contraceptive Development Branch, Center for Population Research, National Institute of Child Health and Human Development.

\section{References}

1. Bona, C. A. 1992. Molecular mimicry of self-antigens. In Molecular Immunobiology of Self-Reactivity. C. A. Bona and A. K. Kaushik, editors. Marcel Dekker, Inc., New York. 239-246.

2. Oldstone, M. B. A. 1987. Molecular mimicry and autoimmune disease. Cell. 50:819-820.

3. Fujinami, R. S., and M. B. A. Oldstone. 1985. Amino acid homology between the encephalitogenic site of myelin basic protein and virus: mechanism for autoimmunity. Science (Wash. DC). 230:1043-1045.
4. Erlanger, B. F., W. L. Cleveland, N. H. Wassermann, H. H. Ku, B. L. Hill, R. Sarangarajan, R. Rajagopalan, E. Cayanis, I. S. Edelman, and A. S. Penn. 1986. Auto-anti-idotype: a basis for autoimmunity and a strategy for anti-receptor antibodies. Immunol. Rev. 94:23-37.

5. Fairchild, P. J., and D. C. Wraith. 1992. Peptide-MHC interaction in autoimmunity. Curr. Opin. Immunol. 4:748-753.

6. Rhim, S. H., S. E. Millar, F. Robey, J. Dean, P. Allen, T. Yule, A. M. Luo, Y. H. Lou, and K. S. K. Tung. 1992. Autoimmune disease of the ovary induced by a ZP3 peptide from the mouse zona pellucida. J. Clin. Invest. 89:28-35.

7. Dean, J. 1992. Biology of mammalian fertilization: role of the zona pellucida. J. Clin. Invest. 89:1055-1059.

8. Ringuette, M. J., M. E. Chamberlin, A. W. Baur, D. A. Sobieski, and J. Dean. 1988. Molecular analysis of cDNA coding for ZP3, a sperm binding protein of the mouse zona pellucida. Dev. Biol. 127:287-295.

9. Millar, S. E., S. M. Chamow, A. W. Baur, C. Oliver, F. Robey, and J. Dean. 1989. Vaccination with a synthetic zona pellucida peptide produces long-term contraception in female mice. Science (Wash. DC). 246:935-938.

10. Tung, K. S. K., and C. Y. Lu. 1991. Immunologic basis of reproductive failure. In Pathology of Reproductive Failure. F. T. Kraus, I. Damjanov, and N. Kaufman, editors. Williams and Wilkins, New York. 308-333.

11. LaBerbera, A. R., M. M. Miller, C. Ober, and R. W. Rebar. 1988. Autoimmune etiology in premature ovarian failure. Am. J. Reprod. Immunol. 16:115122.

12. Hunt, D. F., R. A. Henderson, J. Shabanowitz, K. Sakaguchi, H. Michel, N. Sevilir, A. L. Cox, E. Appella, and V. H. Engelhard. 1992. Characterization of peptides bound to the Class I MHC molecule HLA-A2.1 by mass spectrometry. Science (Wash. DC). 255:1261-1263.

13. Yule, T. D., and K. S. K. Tung. 1993. Experimental autoimmune orchitis induced by testis and sperm antigen-specific $T$ cell clones: an important pathogenic cytokine is tumor necrosis factor. Endocrinology. In press.

14. LaPolla, R. J., K. M. Mayne, and N. Davidson. 1984. Nicotinic acetylcholine receptor delta chain precursor-mouse. Proc. Natl. Acad. Sci. USA. 81:7970-7974.

15. Yu, L., R. J. LaPolla, and N. Davidson. 1986. Nicotinic acetylcholine receptor gamma chain precursor-Mouse. Nucleic Acids Res. 14:3539-3555.

15a.Lou, Y-H., and K. S. K. Tung. 1993. T cell epitope of a self protein elicits autoantibody to the protein antigen: implications for antigen mimicry and antibody specificity in autoimmunity. J. Immunol. In press.

16. Smith, H., Y.-H. Lou, P. Lacy, and K. S. K. Tung. 1992. Tolerance mechanism in experimental ovarian and gastric autoimmune diseases. J. Immunol. 149:2212-2218.

17. Jorgensen, J. L., P. A. Reay, E. W. Ehrich, and M. M. Davis. 1992. Molecular components of T-cell recognition. Annu. Rev. Immunol. 10:835-873.

18. Wraith, D. C., B. Bruun, and P. J. Fairchild. 1992. Cross-reactive antigen recognition by an encephalitogenic T cell receptor. J. Immunol. 149:3765-3770.

19. van de Rijin, I., A. S. Bleiveis, and J. B. Zabriskie. 1976. Antigens in streptoccoccus mutants cross-reactive with human heart muscle. J. Dent. Res. 55:C59-C64.

20. Singh, V. K., K. Yamaki, T. Abe, and T. Shinohara. 1989. Molecular mimicry between uveitopathogenic site of retinal S-antigen and $E$. coli protein: induction of experimental autoimmune uveitis and lymphocyte cross-reaction. Cell. Immunol. 122:262-273.

21. Lorenz, R. G., A. N. Tyler, and P. M. Allen. 1989. Reconstruction of the immunogenic peptide RNase (43-56) by identification and transfer of the critical residues into an unrelated peptide backbone. J. Exp. Med. 170:203-215.

22. Gautam, A. M., C. I. Pearson, D. E. Smilek, L. Steinman, and H. O. McDevitt. 1992. A polyalanine peptide with only five native myelin basic protein residues induces autoimmune encephalomyelitis. J. Exp. Med. 176:605-609.

23. Chamberlin, M. E., and J. Dean. 1990. Human homolog of the mouse sperm receptor. Proc. Natl. Acad. Sci. USA. 87:6014-6018.

24. Arnon, R., and R. J. Horwitz. 1992. Synthetic peptides as vaccines. Curr. Opin. Immunol. 4:449-453.

25. Kohno, S., J. A. Munoz, T. M. Williams, C. Teuscher, C. C. A. Bernard, and K. S. K. Tung. 1983. Immunopathology of murine experimental allergic orchitis. J. Immunol. 130:2675-2682.

26. Gammon, G., and E. Sercarz. 1992. How some T cells escape tolerance induction. Nature (Lond.). 342:183-185.

27. Lipham, W. J., T. M. Redmond, H. Takahashi, J. A. Berzofsky, B. Wiggert, G. J. Chader, and I. Gery. 1991. Recognition of peptides that are immunopathogenic but cryptic. J. Immunol. 146:3757-3762.

28. Oldstone, M. B. A., M. Nerenberg, P. Southern, J. Price, and H. Lewicki. 1991. Virus infection triggers insulin-dependent diabetes mellius in a transgenic model: role of anti-self (virus) immune response. Cell. 65:319-331.

29. Ohashi, P. S., S. Oehen, K. Buerki, H. Pircher, C. T. Ohashi, B. Odermatt, B. Malissen, R. M. Zinkernagel, and H. Hengartner. 1991. Ablation of "tolerance" and induction of diabetes by virus infection in viral antigen transgenic mice. Cell. 65:305-317.

30. Rocken, M., Urban, J. F., and Shevach, E. M. 1992. Infection breaks T-cell tolerance. Nature (Lond.). 359:79-82.

31. Paliard, X., S. G. West, J. A. Lefferty, J. R. Clements, J. W. Kappler, P. Marrack, and B. L. Kotzin. 1991. Evidence for the effects of a superantigen in rheumatoid arthritis. Science (Wash. DC). 253:325-329. 